\begin{tabular}{|c|c|c|c|}
\hline & $\begin{array}{r}\text { D } \\
\text { Anna } \\
\text { http://wv }\end{array}$ & $\begin{array}{l}3.2 .2 \\
\text { Journal } \\
\text { s/index.php }\end{array}$ & 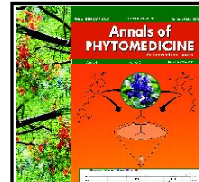 \\
\hline & Print ISSN : 2278-9839 & Online ISSN : 2393-9885 & 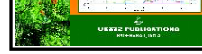 \\
\hline
\end{tabular}

Invited article

\title{
Herbs that heal Spices: The hoard of natural remedies
}

\author{
Afroz Alam* \\ Department of Bioscience and Biotechnology, Banasthali Vidyapith, Banasthali-304022, Rajasthan, India
}

Received October 2, 2019: Revised November 30, 2019: Accepted December 3, 2019: Published online December 30,2019

\begin{abstract}
Plants and humans have cherished a great association ever since their beginning of this planet. Our planet is called green planet just because of the green boon given to us by Mother Nature. Plants fulfill almost every need of humans and other life present on this planet. Through finely woven ecosystems with well formed trophic levels, humans are getting precious offering in the form of plants, including their food, feed, shelter and most significantly the medicines to cure various ailments. In this review an attempt has been made to highlight just only three common kitchen's spices that have valuable aspects as medicinal herbs, viz., Cinnamomum verum J. Presl (Dalchini), Trigonella foenum-graecum L. (Methi) and Crocus sativus L. (Kesar). An all inclusive account of these three is given related to their potential as natural medicines.
\end{abstract}

Key words: Cinnamomum verum J. Presl, Trigonella foenum-graecum L., Crocus sativus L., spices, herbs, medicinal properties

\section{Introduction}

From the starting point of existence of humans, man became close to plants and utilized them in different ways throughout the ages. Initially, the ancient man started to use plants for food, shelter, feed, clothing, flavoring agents, fertilizer and then also accepted some of the plants, usually spices as medicines. In every nation, the diverse domestic as well as commercial kitchens are the reservoirs of many different spices which are used in different recipes. These spices not only give a particular flavor to the food, but also unknowingly treat various ailments. That is why; spices became the indispensable items for every household. This association between spices and human had grown up and many spices approached to be status of medicinal herbs. India, a country with huge societal, religious, floral and faunal diversity, also has a huge treasure of medicinal spices (indigenous as well as exotic), and hence usually known as the 'Medicinal Garden of the World' (Shakya, 2016).

\section{Spices}

The narrative of spices as flavoring materials is one of the dreamiest episodes in the olden times of plant produces. Historically, spices have been as passionately required after the gold. The obsession for spices has been instrumental in human progress, and has changed the track of history and characteristics by promoting intercontinental relations. The finding of new ways and of short cuts routes of trade

Author for correspondence: Dr. Afroz Alam

Department of Bioscience and Biotechnology, Banasthali Vidyapith, Banasthali-304022, Rajasthan, India

E-mail: afrozalamsafvi@gmail.com

Tel.: +91-9785453594

Copyright (C) 2019 Ukaaz Publications. All rights reserved.

Email: ukaaz@yahoo.com; Website: www.ukaazpublications.com and the immigration to the spice-producing nations have resulted due to the immense interest of humans towards the aromatic plants. They have an important part in all the civilizations of olden days, especially, in ancient countries like India, China, Babylon, Egypt, Rome and Greece. The bulk of spices cultivated in the Asiatic tropics and was among the foremost articles to buy and sell among the East and the West nations (Alam and Sharma, 2012).

Though, spices have nutritive value, yet they cannot be categorized as foods owing to their requirement in a small amount, just to add essence and fragrance to the food. They arouse the desire for food and augment the gush of the gastric juices. Hence, they are frequently referred to as food garnishes.

The medicinal value of spices was not known to the local populace, but the conventional medicine men have used many of the spices in the Middle Ages to cure various diseases, later on, a substantial number of spices have recognized as certified drugs in Asia (Sharma and Alam, 2018).

\section{Medicinal value of spices}

The term of medicinal plants includes a group of diverse plants that have valuable medicinal properties. Medicinal plants are considered as a "backbone" of traditional medicinal systems. According to an estimate, around 3.3 billion people, especially, in developing countries used medicinal plants regularly to heal various ailments. It was believed that about $80 \%$ of the more than 5.2 billion people of the world reside in poorly developed countries and World Health Organization (WHO) determined that $80 \%$ of these people depend solely on traditional medicines for their major healthcare requirements (Ahvazi et al., 2012). Since, they have deprived from advanced drugs therefore they have absolute believe that the plants are abundant sources medicines. 
In current circumstances the developed nations also looking for plant derived herbal drugs as a potent and safest prospect for various diseases including some incurable ailments also. As a result now a rapid swing has been evident in recent past and many pharmaceuticals companies have started their herbal divisions which are working to extract the active compounds to be used for synthesis and development of novel drugs (Singh, 2015; Nooreen et al., 2018).

From spices, the plant parts which have been used either as flavoring agents or to synthesize drugs can be root, leaf, fruit, flower, and different types of seeds, or may be the whole plant, whichever is useful to maintain health and to treat the diseases (Jamshidi-Kia et al., 2018).

Globally, now the traditional medicinal systems have become a topic of comprehensive significance and researches on herbal drugs are on full swing. As a result ethnobotany is again finding place in research arena in many countries. Tribals are now getting attention by multinational companies because they have the knowledge about the precious uses of many locally grown plants. In India, there is huge floral diversity, about 18,000 species of flowering plants are known, out of which about 8,000 species have medicinal value and are utilized by the village communities especially tribal communities as spices and also in traditional system of medicines, for example the Ayurveda, Siddha, etc. (Singh, 2015).

Historically, the preliminary written proof regarding usage of spices/ herbs for manufacturing drugs was found to be on Sumerian Clay slab from Nagpur about 5000 years ago. In some manuscripts, Egyptians and Chinese were the first human beings who had started to use plants as medicines. These plants were earlier used by Greek people also. Hippocrates, the inventor of Greek Medicine and Aristotle, student of Hippocrates used medicinal plants for the cure of diseases. It was followed by Theophrastus, a Greek Scientist who established the School of Medicinal Plants (Jamshidi-Kia et al., 2018).

Due to the easy availability of the herbal drugs at a price much lower than that of the modern synthetic drugs, they can reach easily to the common man. The WHO declares and promotes the use of herbal drugs in national health care programs as they are time tested and are regarded to be much safer as compared to modern synthetic drugs (Dar et al., 2017).

In this article three of the common spices, viz., Cinnamomum verum J. Presl, Trigonella foenum-graecum L., Crocus sativus L. have been described as phyto-medicines for their medicinal properties and curing potential with all inclusive account.

\subsection{Cinnamomum verum J. Presl}

\subsubsection{Chemical constituents}

The Cinnamon is consisting of numerous resinous components such as cinnamaldehyde, cinnamate, cinnamic acid and lots of essential oils (Senanayake et al., 1978). Singh et al. (2007) had reported the presence of spicy taste and fragrance is mainly due to the availability of cinnamaldehyde and occurs because of consumption of oxygen. As the Cinnamon gets older, its colour darkens, which improves the resinous compounds. Numerous physiochemical properties of Cinnamon were reported for instance, the presence of a wide variety of essential oils like transcinnamaldehyde, cinnamyl acetate, eugenol, L-borneol, caryophyllene oxide, b-caryophyllene, L-boranyl acetate, E-nerolidol, alpha-terpinol, alpha-cubebene, terpinolene and alpha-thujene (Figure 1) were reported (Cardoso-Ugarte et al., 2016). Mallavarapu et al. (1995) studied those 53 constituents which generally includes one of the major components, i.e. Eugenol (81-84.5\%) found in leaves of cinnamon oil. The fruits of cinnamon are found to be aromatic and having a sweet spicy aroma. (E)-cinnamyl acetate (42-54\%) and (E)-caryophyllene (9$14 \%)$ are the major components which are identified in cinnamon oil as thirty-four compounds (Figure 1).

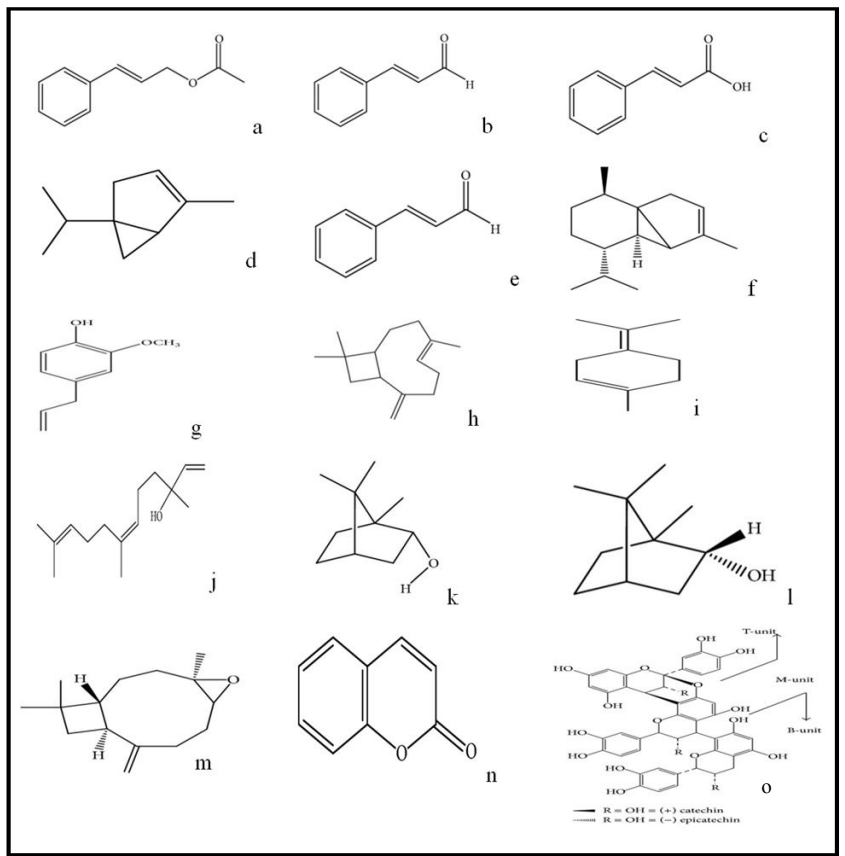

Figure 1: Cinnamyl group-containing compounds: a) Cinnamyl acetate, b) Cinnamic acid, c) Cinnamaldehyde; Endocyclic double bond-containing compounds: d) $\alpha$-Thujene, e) $\alpha$ Terpineol, f) $\alpha$-Cubebene; Unconjugated exocyclic double bond-containing compounds: g) Eugenol, h) $\beta$-Caryophyllene, i) Terpinolene; Hydroxy-substituted aliphatic compounds: j) E-Nerolidol, k) L-Borneol, 1) Borneol; Other miscellaneous compounds containing oxirane, 2-pyranone, and pyran groups: m) Caryophyllene oxide, n) Coumarin, o) Procyanidin type-A polymer

\subsubsection{Health benefits of Cinnamon}

The Cinnamon is commonly used as spice without having any side effects in daily life. Many reports were dealing with the various properties of the Cinnamon which are generally in the form of bark, essential oils, bark powder, phenolic compounds, flavonoids as well as isolated components (Jayaprakasha et al., 2000; Cheng et al., 2009). Advancement of human health is being promoted by some unique properties of Cinnamon. The actions which are occurring, in which oxidants and microbes is the result of antioxidants and antimicrobial activities. The receptor mediated mechanism is responsible for anti-inflammatory, anticancer and antidiabetic activities. Many health benefits of various species of Cinnamon have been found (Cheng et al., 2006). Many investigations are 
being provided for additional evidence of clinical processes for the traditional use of Cinnamon against various diseases such as Cancer and inflammatory, cardioprotective and neurological disorders (Gruenwald et al., 2010). The bark of the stem is generally working as a flavoring agent (Duke, 1983). Used for adding flavour in curries and numerous sweet dishes. The leaves and bark are responsible for the formation of essential oils which works as food flavoring agent in various food products such as sauces, pickles, baked foods, soft drinks and confectionaries (Thomson et al., 2003). The Cinnamon flavor is imparted by using leaves.

The fruits, buds and fruit stalk of the Cinnamomum verum showed many analogies and this analogy was reported that synthetic (E)cinnamyl acetate is having excellent sensory and fixative properties so used in perfumery.

It was studied that during the bud stage mevalonic acid metabolites are formed at a maximum extent and are also increased up to some extent in the fruit stage but these are different from oils of different parts of Cinnamomum verum like leaf, root bark and stem bark. There may be some similarity because these compounds may be present in other oils (Mathew and Abraham, 2006). Hence, the fruit stalk of Cinnamomum verum contains (E)-cinnamyl acetate and (E)-caryophyllene which composes the major component. (E)cinnamyl acetate is substitute for the synthetic (E)-cinnamyl acetate which is generally a flavouring agent in liquors and confectionaries (Paranagama et al., 2010). Dugoua et al. (2007) reported about the competence and safety of Cassia cinnamon bark. Cinnamomum verum is one of the best used spice and the flavouring agent. They are earlier imported to Egypt from China in 200BC. This was mentioned in Bible (Exodus and Proverbs) and 4000 years back was written in Chinese texts (Leeung and Foster, 1996; Torrizuka, 1998).

\subsubsection{Specific uses of medicinal importance}

The barks are commonly used as spices and also for the treatment of cardiac diseases and various types of cancers (Kuete et al., 2017). In the oil obtained from stem bark Cinnamaldehyde $(1 ; 75 \%)$ and camphor (56\%) are the major compounds, respectively (Al-Asmari et al., 2015). The extract of Cinnamon hinders the creation of toxic $\mathrm{A} \beta$ oligomers and averts the letahality of $\mathrm{A} \beta$ on neuronal PC12 cells (Hamidpour et al., 2015). Oral doses of cinnamon extract encouraged the decline of plaques and enhancement in cognitive activities to insistent transgenic mice affected by Alzheimer's disease (Ferlay et al., 2010). The avoidance or cure of Alzheimer's disease is mostly based on drugs reticence of cholinesterase role or creation of amyloid plaque. Diseases related to the nervous system, for example Alzheimer's disease and Parkinson's disease (Li et al., 2012) can upshot when tau proteins become faulty and no longer alleviate microtubules properly. Certain phytochemicals that are able to avoid the tau gathering may be a key aspect in the progress of new drugs (Peterson et al., 2009), the extract of Cinnamon was reported to inhibit the accumulation of human tau in vitro (Peterson et al., 2009).

\subsubsection{Hypoglycemic effect}

Till date, different species of Cinnamomum have been made known to get better glycemic response in vigorous and type 2 diabetic individuals. Recently, it was shown that Cinnamon tea can considerably lower postprandial upper limit of glucose concentration and difference of maximum glucose levels on nondiabetic adults. Furthermore, the powder of cinnamon confirmed valuable effects after adding up to high-sugar foods, lessening the postprandial blood glucose levels. In diabetic persons, doses of aqueous cinnamon extract with oral taken antidiabetics medicines have shown a remarkable decrease in fasting blood glucose (FBG). Hence, based on certain evidence, cinnamaldehyde dose was found to decrease fasting blood glucose levels and improve hyperinsulinemia levels. In addition, this bioactive cinnamaldehyde could also be useful in curing diabetes disease in the course of declined glycosylated hemoglobin (HbAlc). Proantocyanidins, a chemical present in aqueous extract of cinnamon, have also been reported to have positive effect on hypoglyaemic condition. There are numerous proposed methods for the hypoglycemic consequence of cinnamon and its isolated phytoconstituents. These comprise insulin-mimetic act through signaling pathway regulations. Compounds found in Cinnamon tea are able to enhance the GLUT4 translocation by adjusting uptake of glucose in muscles and adipose tissues. This extract also encourages glycogen production via downregulation of phosphoenolpyruvate carboxykinase in the liver. An additional probable method of action of cinnamon and its bioactive constituents connecting to its hypoglycemic effect is associated with a decline in intestinal glycosidase action thus, adjusting absorption of glucose and postprandial blood glucose level (Roussel et al., 2009).

\subsubsection{Antioxidant activity}

Foodstuffs which are present in antioxidant compounds plays important role in the life of a human being, protects health. These are also used as key additives in oils and fats (Mancini-Filho et al., 1998). Rapid consideration is being received by spices and medicinal plants acting as a source of essential antioxidants against many diseases (Suhaj, 2006). The most essential part for the progress and human existence is antioxidants as they keep on responding to free radicals and metabolism related diseases as well as some syndrome related to the age of the humans and animals. It has been reported that numerous parts of Cinnamon in solvents like ether, aqueous and methanolic extracts showing different activities of antioxidant (Mancini-Filho et al., 1998).

\subsubsection{Anti-inflammatory activities}

A study reported that some chemical compounds are isolated from the bark of C. cassia which exhibits the inhibition of the nitric oxide production, which is done by stopping the nuclear factor kappa light chain enhancer having activates B cells, which indicates some substances which are used as anti-inflammatory agent (Lee et al., 2002). Mancini-Filho et al. (1998), Lopez et al. (2005), and Shan et al. (2005) reported that Cinnamomum verum is found to be safe if ingested, having many pharmacological properties which are making it more efficient. Rao and Gan (2014) reported that the Cinnamomum verum contains many essential oils and many more derivatives such as cinnamaldehyde, cinnamic acid, and cinnamate. Osuna et al. (2005) reported that the richest bioresources are the medicinal plants of drugs traditionally for the system of medicine, modern medicine, nutraceuticals, food supplements, folk medicines, pharmaceutical intermediates and chemical entities for synthetic drugs. 
This spice lowers the cholesterol, reduces the blood sugar level, cures heart diseases, fights with Cancer, act as a mouth freshener, cures respiratory problems and act as antidiuretic. Rheumatism, Arthritis and stiffness can be cured by Ayurvedic medicines which are prepared using Cinnamomum verum. This is one of the multipurpose medicinal spices. Ranasingha et al. (2005) reported that the availability of the evidences of the in vitro and in vivo suggests that $C$. verum has many antiparasitic, antibacterial, antioxidant, and free radical scavenging properties. Nahavi et al. (2015) reported that the antibacterial effects of the cinnamon from farm to food, cosmetics and pharmaceutical industries. Herbs and spices are not only used as the antioxidants and agents for adding flavors but show some antimicrobial activity for destroying the food borne pathogen and food spoiling bacteria.

The effects of bioactive constituents are essential. Vazirian et al. (2015) reported the antimicrobial effect of Cinnamon bark essential oil in cream-filled cakes and pastries. The gas chromatography is used for the determination of the chemical constituents. He also identified 25 components such as cinnamaldehyde (79.73\%), linalool (4.08\%), cinnamaldehyde paramethoxy (2.66\%), eugenol (2.37\%), and trans caryophyllene $(2.05 \%)$ are the most important constituents.

Hamidpour et al. (2015) reported that cinnamon is one of the potent anticancer drugs. The second leading cause for the death in United Kingdom and United States is Cancer. They also possess antioxidant activity. The most bioactive compound of Cinnamomum burmannii is trans cinnamaldehyde. No in vivo works are found for antitumor activity. Mollazadeg and Hosseinzadeh (2016) studied the effects of cinnamon on metabolic syndrome. The insulin resistance and hyperglycaemia, central obesity, high blood pressure, dyslopidemia, lower levels of high-density lipoprotein cholesterol and hypertriglyceridemia are included in a condition called as metabolic syndrome.

Due to cardiovascular diseases morbidity and mobility can be presented. Manoranjotham et al. (2016) studied the medicinal bark which is used for curing coronary heart diseases in Malayali Tribes, Panchamalai hills, Tamil Nadu, India. Presently, bioactive components are being studied in the bark extract of Cinnamomum verum using UV-VIS and FTIR analysis. The functional groups of the active components which are present in the plant are identified by FTIR. Vabilwala et al. (2017) studied the phytochemical analysis and antimicrobial activity of Cinnamomum verum. The extracts of methanolic and chloroform of Cinnamomum verum were screened for checking the antimicrobial activity and phytochemical analysis. Chloroform extract shows more antibiotic activity as compared to the methanolic extract. The potential source for antimicrobial agent can be chloroform. Balijepalli et al. (2017) studied about the Cinnamomum genus. The more studies on the bioactive components and their activities is needed. Many species of Cinnamomum verum are used as traditional medicine (Reddy et al., 2017).

Recently, Kamran et al. (2018) studied the biogenic synthesis characterization and investigation of photocatalytic and antimicrobial activity of manganese nanoparticles synthesized from Cinnamomum verum bark extract. Abdalla Wisal (2018) studied the antibacterial and antifungal effects of the cinnamon. They are not only used for cooking purposes but are also used for the preparation of medicines. Many foods borne diseases like upset stomach, diarrhoea, vomiting can be cured by Cinnamon. Cinnamon is used as anti-inflammatory, namaticidal, antitermitic, mosquito larvicidal, insecticidal, antimycotic and anticancer agent. It is also used as tooth powder for curing tooth aches and other dental problems. Vazirian et al. (2015) has shattered the effects of the different species of Cinnamon on Candida albicans.

\subsubsection{Other important activities}

Yang et al. (2019) has recently studied the disruption in KPCproducing Klebsiella pneumoniae membrane by the induction of the oxidative stress by the bark of the cinnamon (Cinnamomum verum J. Presl) essential oil. The most nosocomial pathogen is Klebsiella pneumoniae (KP) and the carbapenemase (KPC) is being carried. Protein identification, quantification and its data analysis are also reported. The cDNA synthesis and RNA extraction are also studied.

\subsubsection{Common medicinal uses of Cinnamon}

The oil of Cinnamon bark is used in various dental and pharmaceutical problems (Guardia et al., 2001). In earlier times, Cinnamon were used as tonic, as a sedative during childbirth and have remedy for various disorders. This also acts as a breath sweetener (Jakhetia et al., 2010). Distillation of Cinnamon was done for the production of Cordials, and also used for solving digestion problem in the medieval period. Some local remedies such as gastrointestinal as well as some respiratory problems can be cured by using Cinnamon and its other species during Orient. It is used for headache relief mostly in the Philippines and the Pacific regions. Parturition speed is increased by chewing Cinnamon in Colombia. In Ghana, the young shoots bark is used as carminative and for treating catarrah (coryza), the extract of bark act as an intestinal astringent. In Halti, the border between Norway and Finland, the cinnamon paste is used externally as poultice to get relieve in the conditions of joint pain. In the cases of intestinal spasms and stomach gas it is also taken orally (Guardia et al., 2001).

\section{Trigonella foenum-graecum L. [Fenugreek (Methi)]}

Trigonella foenum-graecum L. [Fenugreek (Methi in Hindi) is an indispensable ingredient of Indian spices used in food not only for the taste enhancement of the foodstuffs, but also it provides some proven health benefits. Conventionally, it is used in preparing food to prevent certain common diseases like flatulence, bloating, indigestion, intestinal gas, cramps, diabetes, arthritis, fatty liver, cancer, high blood pressure, and several other disorders. In Ayurvedic system of medicine, it is a frequently used ingredient to treat all many diseases.

The main action of Fenugreek comes into view on the digestive system. The regular use of this herb regulates the gastric juices and boosts the bile flow from the liver. The supplementary action of this herb is pragmatic on the body fluids and blood. It is a natural blood purifier and vastly suggested for the patients with the 
increased levels of uric acid in the blood (Basu et al., 2014). At the present time, it becomes accepted for managing diabetes mellitus. It is also a useful remedy for the joint pain caused in the cases of rheumatoid arthritis. It reduces tenderness, inflammation, ache and inflexibility effectively.

\subsection{Plant parts of medicinal value}

Seeds of Fenugreek (Methi) are most commonly used as Ayurvedic medicine and folk medicine as well. The dried leaves of fenugreek are known as 'Kasuri Methi' commonly used as a flavoring agent and for treating digestive disorder in Ayurveda. Overall, seeds have been used mainly for medicinal purposes while the leaves are frequently used as food additive. The oil extracted from the seeds is also used to cure diabetes, muscle tremor, enhancing lactation in females. Nowadays, the oil is also offered as capsules (Acharya et al., 2016).

\subsection{Phytochemistry}

Fenugreek seeds contain 4-Hydroxyisoleucine, Trigonelline, Trigoneosides and Galactomannan, which acts on the glucose metabolism and likely to be responsible for lowering the blood glucose level. The active constituents of Fenugreek contain 4-Hydroxyisoleucine, Diosgenin, Gallic Acid, Protocatechuic Acid, Protodioscin, Quinic Acid, Trigonelline, Trigoneosides, Yamogenin, Trypsin, Chymotrypsin.

The fenugreek oil contains following active constituents: Neryl Acetate (17.32\%), Camphor (16.32\%), $\beta$-Pinene (15.05\%), $\beta$ Caryophyllene (14.63\%), 2,5-Dimethylpyrazine (6.14\%), Geranial (4.81\%), 6-Methyl-5-Hepten-2-One (4.48\%), 3-Octen-2-One (4.32\%), A-Selinene (4.04\%), $\alpha$-Terpineol (2.77\%), $\alpha$-Campholenal (2.63\%), $\alpha$-Pinene (2.61\%), $\gamma$-Terpinene $(2.08 \%)$.

\subsection{Nutritional value of seeds}

Fenugreek seeds hold a fine quantity of dietary fiber. The fiber content of fenugreek also contains non-starch polysaccharides (NSP) as well as saponins, tannin, mucilage, hemicelluloses and pectin. Protein content is extremely unpredictable in the fenugreek seeds and it ranges 2-5 grams to 10 grams of seeds. However, it contains plentiful amounts of linoleic acid, oleic acid, and linolenic acid. Vitamins A, C, D, E, K, B6, B12, Riboflavin, Niacin, Folate, Pantothenic Acid, Choline, Betaine, etc. Minerals like Ca, Fe, Mg, P, $\mathrm{K}, \mathrm{Mn}, \mathrm{Zn}, \mathrm{Cu}, \mathrm{Se}$, and Fluoride are present in substantial amounts.

\subsection{Pharmacological actions}

Fenugreek majorly acts on the digestive system. It normalizes the secretion of gastric juices and enhances bile secretion. It elevates the peristalsis movement of the intestines, thus gives strength to the entire alimentary canal, which facilitates the improve contractions. It also works as a tonic for the intestine, stomach, gall bladder, liver and pancreas, thus it improves overall metabolic activities of these organs (Acharya et al., 2011).

\subsubsection{Therapeutic indications}

Fenugreek (Methi) reduces following symptoms: Body aches, Pain, Nervine weakness, Inflammation, Gas formation in the alimentary canal, and poor appetite (due to the decreased secretions bile salts or reduced liver functions) (Acharya et al., 2007).

It contains powerful antimicrobial, antioxidant, antidiabetic, and anti-carcinogenic activities, which assist in the treatment and prevention of several diseases. The use of seeds has been recommended in the anti-hyperglycemic condition, as pancreatic stimulant, as anti-diabetic; anti-inflammatory; analgesic agent, as nervine tonic due to its neuroprotective properties. Seeds are also used as for their antioxidant, anti-carcinogenic, antimicrobial, digestive stimulant, and carminative, antispasmodic, anti-rheumatic potential. In cases of galactagogue, emmenagogue and sialagogue the seeds have been frequently used (Mehrafarin et al., 2010).

\subsection{Ayurvedic properties of fenugreek seeds}

According to Ayurvedic system, Fenugreek is a most appropriate medication for people with Vata type body organization or having indications of surplus or goaded Vata Dosha. It may not be appropriate for inhabitants with Pitta body type or having surfeit or provoked Pitta symptoms. Methi is expected to balance the Kapha Dosha in the body organization. In cases of people with Pitta body type, fenugreek can be given, but it should be kept in mind to begin with lower dosage $(<1$ gram per day) furthermore dosage should be steadily amplified as per acceptance of the body type. Moreover, it is important that seeds should be saturated with water at least for $12 \mathrm{~h}$ before its use by the people. Soaked Fenugreek seeds are less expected to influence Pitta at a noteworthy intensity (Acharya et al., 2011).

\subsubsection{Indications of fenugreek (Methi) seeds}

Fenugreek (Methi) seed are useful in many health conditions, viz., Intestinal gas, flatulence, or abdominal distension, Loss of appetite (due to the decreased secretions bile salts or reduced liver functions), Abdominal heaviness after meal, Diabetes Mellitus, Rheumatoid Arthritis, Constipation, Metabolic disorders, Debility after delivery (characterized by vertigo, loss of appetite, pain in hands and feet, backache, sore muscles, etc.), Leucorrhoea, Body pain, Appendicitis, Hair fall, untimely whitening of hair, Enuresis, Tonsillitis, Mumps, Dark Circles (Ahmad et al., 2010).

\subsection{Properties of fenugreek leaves}

The Fenugreek leaves have cool potency and do not report to amplify 'Pitta Dosha' like the seeds. Rest of the medicinal properties and uses are same as of its seeds. The fenugreek leaves are found to be more useful carminative than the seeds. In addition, leaves possess antacid, digestive and anti-inflammatory properties. (Duke, 1986).

\subsubsection{Indications of fenugreek leaves}

Fenugreek leaves are beneficial in following diseases: Polyuria, Hyperacidity, heartburn or dyspepsia, Enuresis (along with Acacia Catechu extract), Dandruff (fenugreek leaves paste is applied on the scalp), and hair fall or whitening of hair (Ethan et al., 2003).

\subsection{Fenugreek benefits and uses}

Seeds and leaves of Fenugreek help in the digestive problems, as they prevent the symptoms of gastrointestinal disturbances like abdominal pain, flatulence, nausea, vomiting, and abdominal 
distention. It also perks up the secretion of digestive enzymes, therefore improving the amalgamation of indispensable nutrients from the foods into the blood stream (Petropoulos, 2002). The most common health benefits and medicinal uses of fenugreek are described below.

\subsubsection{Diabetes mellitus}

The seeds of Fenugreek are identified to have potent anti-diabetic characteristics. It can help in controlling the blood sugar levels in the cases of diabetes type-1 and type-2. This blood sugar lowering upshot of seeds can be given to galactomannan (galactose+mannose), a soluble fiber found in seeds. It decreases the absorption rate of carbohydrates (sugars) into blood hence prevents the increment in blood sugar levels. It also improves the glycemic control and diminishes the insulin confrontation in the patients having type 2 diabetes mellitus. Fenugreek seeds contain 4-hydroxyisoleucine (amino acid) along with added compounds like trigonelline and trigoneoside, which boost up the insulin generation in the pancreas hence, the menace of rigorous hypoglycemia becomes very low in the patients who regularly use seed of Fenugreek. Also, the blood-sugar lowering effect is absent in the non-diabetic people (Sharma et al., 1990).

The peroxidation of lipids in the tissues or cells is also considered accountable for the meager utilize of insulin, which results into insensitivity to insulin. Fenugreek has antioxidant action and decreases lipid peroxidation. This act assists to lessen insulin insensitivity and encourages the proper and efficient use of the secreted insulin. Thus, additional doses of fenugreek seeds can perk up the glycemic control and lessen the insulin confrontation in the diabetic patients (Sharma et al., 1996).

\subsubsection{Digestive system related ailments}

Fenugreek seeds have a fine quantity of non-starch polysaccharides (NSP) along with mucilaginous fiber. These fibers help in unproblematic bowel movement by escalating bulk formation. In Ayurveda, it is evident that the fenugreek gives potency to the intestinal wall and improves peristaltic movement of intestine. In case of constipation, around 3 grams fenugreek seeds which are soaked for $12 \mathrm{~h}$ should be eaten at night just prior to the sleep. On the other hand, powder of seeds can also be used with Luke warm water (around 3 grams) at night to get rid of irritating condition of constipation (Basch et al., 2003). Fenugreek seeds are known to reduce oppressive mucus in the stool by raising the bile secretion into the intestine from the liver, which assists to recuperate fat metabolism and acts as an effective digestive for oily intakes as food. Taking around 3 grams fenugreek seed powder along with a pinch of black pepper powder improves the effectiveness of the fenugreek in cases of sticky and slimy stool. This combination is also advantageous for persons who do not experience absolute evacuation. The incidence of greasy stools can be a sign of reduced assimilation and ailing digestion. Fenugreek improves absorption and metabolism of fat hence reduce the feeling of awkwardness in the stomach and assist to sense fresh and relived after a bowel (Acharya et al., 2011).

Fenugreek is found very effective in cases of loose motions with mucus discharge in the stool. Ayurveda considers mal-absorption and meager digestion as the most common causes of mucus discharge in the stool for the duration of diarrhea. Some intestinal infections can also be the causes of this condition. Since, seeds of Fenugreek have digestive act therefore their use perks up the digestion, and also stimulates the emission of the toxic substances from the intestine, which eventually reduces intestinal pain.

Fenugreek also has antimicrobial and anti-inflammatory properties, which further help in the killing the bacteria and other microbes hence control the diarrhea. Further, mucilage fibers of fenugreek help in the improved absorption of the surplus water from the alimentary duct, which reduces the occurrence of the loose motions. Leaf juice of Fenugreek (20 to $40 \mathrm{ml}$ with 5 grams sugar) is also found useful in managing the diarrhea with burning feeling (Chevassus et al., 2010). Loss of appetite is a common problem which has several causes, but it is mainly due to reduced liver function.

Fenugreek improves functions of liver and augments the digestion by escalating the bile secretion into the small intestine. Fenugreek is an efficient medication for curing acid reflux and indigestion. Even though fenugreek seeds have hot effectiveness, but the high quantity of mucilage in its seeds assists in relieving indigestion by glazing the inner mucosal lining of the stomach and intestine. It relieves the wound up gastrointestinal tissues and provides relief from acid eructation, burning in the throat, tenderness in the abdomen, vomiting, and nausea caused by the reflux of the acidic contents of the stomach into the throat in the patients with Gastroesophageal Reflux Disease (GERD) (Chevallier, 2000).

Leaves of Fenugreek help in the managing peptic ulcers by normalizing the gastric secretion. It neutralizes the surplus acidic secretion in the stomach thus shielding the fragile stomach mucosa from exasperation and ulceration. Both seeds and leaves of fenugreek have effective carminative and anti-flatulent characteristics, which assists to lessen intestinal gas, abdominal distension, flatulence, and feeling of fullness or heaviness of abdomen due to surplus gas buildup in the alimentary canal. Furthermore, it also checks gas formation and thus prevents burping (belching), cramps and bloating (Basch et al., 2003).

\subsubsection{Liver disorders}

Fenugreek seeds contain polyphenols that have liver protective nature and guard the liver from the toxicity caused by various metabolic processes and their byproducts. It also prevents harm to the liver due to continual alcoholism thus sinking the danger of cirrhosis, hepatitis, and fatty liver condition. This herb plays an imperative part in liver detoxification, thus allowing the body to free from the toxins. It rinses out the blood and improves functions of liver; it also protects the liver against the ethanol-induced hepatic damage. By inducing apoptosis this herb helps in the treatment of liver carcinoma (McAnuff et al., 2005; Sakr et al., 2009).

\subsubsection{Colon cancer}

Fenugreek seeds are also known to help in the cure and avoidance of colon cancer. The saponins and mucilage fibers of this herb bind to the toxins present in the foodstuff such as coloring agents, preservatives, etc., and flush them away. This act is very helpful in the protection of the mucosal layer of the colon from the toxins induced cancerous changes. Fenugreek maintains vigorous microbial flora in the colon, which improves its functions and guarantees 
efficient removal of the carcinogenic substances from the intestines through the stools hence reducing the risk of colon cancer (Dinarello, 2006; Lepage et al., 2010).

\subsubsection{Heart health: High cholesterol and triglycerides}

Fenugreek plays a key role as cardio-protecting agent due to the presence of galactomannan in its seeds. The seeds also contain a high amount of potassium, which assists in countering the action of sodium thus regulating the blood pressure and heart rate. The elevated level of potassium facilitates the flow of sodium from the kidneys via urine. Due to the hygroscopic nature of sodium, it pulls itself with water thus ensuing in the removal of elevated quantity of fluids from the body. This process helps to decrease the elevated blood pressure and also assists to control arrhythmias by regulating the heartbeats. Fenugreek acts as potent cholagogues, as it promotes bile secretion from the liver and gallbladder into the small intestine; however the mucilage, saponins, hemicelluloses, pectin and tannins in the fenugreek restrain the re-absorption of the bile salts in the colon. Consequently, it increases the emission of the bile via stool and decreases the rate of cholesterol synthesis in the liver. The more effect appears on LDL-cholesterol with fenugreek use and it improves the lipid profile. Fenugreek is also used to prevent atherosclerosis (a condition characterized by the high levels of cholesterol) leading to the accumulation of plaques along the interior liningd of the arteries. This results into narrowing of the blood vessels thus dropping the blood supply to the vital organs. It can augment the danger of myocardial infarction, peripheral vascular disease (PVD), and sudden stroke. Fenugreek is very helpful in preventing these conditions by checking the cholesterol levels (Moradi kor et al., 2013).

\subsubsection{Rheumatoid arthritis}

Fenugreek has anti-rheumatic and anti-arthritic activities. It is liable to augment superoxide dismutase and glutathione and trim down lipid peroxidation in the cartilage tissue. The Superoxide dismutase prevents the harm to tissues while Glutathione assists in revamping and construction the tissues. Therefore, fenugreek helps to prevent the damage of cartilages. In Ayurveda, fenugreek seeds are known to put forth the pain-relieving and anti-inflammatory action on the joints of the skeletal system. Seeds are effective to reduce joint inflammation, inflexibility, engorgement and ache. Ayurveda system considers that the undigested food constituents and nutrients in the abdomen produce toxic substances in the body, called 'AMA' in Ayurveda are the main causes of rheumatoid arthritis. By reducing AMA and enhancing its removal from the body, fenugreek eventually assists to treat rheumatoid arthritis (Liagre et al., 2004, 2005, 2007).

\subsubsection{Chronic appendicitis}

The roasted seeds of fenugreek are frequently used in persistent appendicitis. The seeds help to decrease abdominal uneasiness, meek abdominal tenderness, soreness, dissatisfaction and tiredness due to this ailment. It also checks severe stress of appendicitis by reducing swelling of appendix and removing the deposits from it.

\subsubsection{Diseases related to mouth}

As an herbal sialagogue, fenugreek induces saliva discharge and encourages the manufacture of added saliva in the mouth therefore used as an effective treatment for the Xerostomia (dry mouth). Excess Kapha Dosha in the mouth causes sweet taste in the mouth in such condition Fenugreek balances Kapha Dosha in the body and also overcomes the unwanted sweetness in the mouth by reducing AMA in the mouth. The decoction of fenugreek is used for gargling and rinsing of the mouth in cases of tonsillitis. The decoction soothes the swollen tonsils and acts as bactericidal, hence reduces bacterial infections. It also has antiviral potential so it is also useful in cases of viral infections.

\subsubsection{Health issues related to females}

In India, Fenugreek seeds are commonly used in the form of 'Methi Laddu' for re-establishing the uterus's normal pre-pregnancy dimension. The use of fenugreek enhances its rapid revitalization of uterus. Fenugreek also assists to cleanse the uterus in new mothers and prevents the usual infections of the reproductive organs. In cases of Leucorrhoea, Fenugreek seed powder promotes uterus depression and contraction of the uterus, which lessens all secondary symptoms and assists to achieve the original normal size of the uterus.

Fenugreek seeds contain phytoestrogens, which amend the hormonal secretions and reinstate the usual hormonal equilibrium. The effect is apparent on all hormones, viz., prolactin, luteinizing hormone, estrogen, progesterone, etc. Fenugreek is expected to rouse the expansion of mammary glands by helping in the making of estrogen in the body and imitating the upshot of phytoestrogen. It can encourage the growth of new breast cells and therefore, amplify the size of the breasts. Thus, fenugreek can be used as a natural option to the aesthetic remedies for breast enlargement.

Fenugreek seeds showed impending guard against breast malignancy by holding back the DMBA-induced hyperplasia of the breast tissues. It also assists in the quicker recuperation of the women with breast cancer by promoting apoptosis of cancerous cells (Shabbeer et al., 2014). It shows noteworthy chemopreventive outcome, which helps to restrain, overturn, and avert the development of the cancer cells into the adjacent regular tissues therefore preventive the degree of this disease. It also acts by averting the process of angiogenesis. Preventing angiogenesis is an imperative facet of cancer management. Fenugreek can assist to stop angiogenesis in the cancer bunch of cells due to which the anomalous cells do not obtain ample supply of blood and other nutrients ensuing in their fatality (Snehlata and Payal, 2011).

\subsubsection{Kidney stones}

Some confirmations suggest that fenugreek can assist in avoiding the formation of kidney stones. It reduces the quantity of calcium oxalate (the main contributor of stone formation) in the kidneys. Fenugreek can also facilitate the exclusion of existing kidney stones by escalating the urine production. The elevated amount of urine generates a pushing force therefore ejecting out the stone through urination (Shekha et al., 2014).

\subsection{Antioxidant effect}

Fenugreek seeds have elevated levels of polyphenolic flavonoids, which have powerful antioxidant action. Seeds contain a high amount of such flavonoids thus fenugreek is accepted as one of the most effective antioxidant herbs. This possession of fenugreek has been 
linked with the guard of erythrocytes from the damage caused by the harmful free radicals. The use of fenugreek seeds jointly with ethanol can emphasize its antioxidant action, which helps to avert the lethal effects of alcohol on the liver. The antioxidant nature of fenugreek also protects the body against the noxious effects of various allergens, environmental contaminants, and the certain preservatives and flavoring agents present in foodstuff. These substances are known to cause harm to the DNA of the vigorous tissues and arouse an anomalous growth of the cells that result in cancer (Thirunavukkarasu et al., 2003).

\section{Crocus sativus L. (Saffron)}

Saffron is a one of the most important medicinal herbs. Its botanical name is Crocus sativus L. Origin of the term Saffron is from the French term 'Safran', which was derived from the Arabic word 'Safranum', means 'yellow' (Gohari et al., 2013). It is a ûowering plant in the Iridaceae family and is commonly known as saffron.

\subsection{Phyto-constituents}

The main active constituent of saffron are: (1) Bitterness principlepicrocin is a very important substance for bitterness decomposition of glycoside by acid hydrolysis give glucose and the volatile a glycane and safranal. (2) Dye material-main constituents are Carotenoid, crocetin (crocin) pharmacological approaches (Figure 2). Earlier it was reported that in ancient times saffron was used as an anticancer agent and the preparation of saffron extracts against different type of tumor and cancers, liver, spleen, kidney, stomach and uterus treated with saffron (Srivastava et al., 2008). Pharmacological study showed that complete absence of any toxicological manifestation in the liver, kidney or bladder (Encyclopaedia Britannica, 1974). Significant activity of crocin and crocetin are their free radical scavenger properties (LiakopulouKyriakides and Kyriakides, 2010). Carotenoids are used in sperm cryopreservation. Gainer and Chisolm (1974) demonstrated that crocetin binds strongly to the albumin and reduce the effect of the atherosclerosis and increase oxygen diffusivity. Three potential therapeutic applications of saffron are antitumor, hypolipidaemic and tissue oxygenation enhancement (Figure 2).

Escribano et al. (1996) experimentally studied that the cytological effect of a glycoconjugate extracted from corms of saffron plant $(C$. sativus) on human cell lines in culture. Corms of $C$. sativus contain a glycoconjucate that show cytotoxicity activity on tumoral cells in culture. Study of intracellular calcium fluctuations, and release of lactate dehydrogenase in human cervical epitheloid carcinoma cells, showed that this compound caused plasma membrane damaged, allowing moments of both calcium and macromolecules, and leading to cell lysis. Analysis of DNA fragmentation showed that cell death was not mediated by apoptosis (Nair et al., 1991). This molecule is active against human tumoral cells derived from fibrocarsoma, cervical epitheloid carcinoma and breast carcinoma, with $\mathrm{IC}_{50}$ values of 7,9 and $22 \mu \mathrm{g} / \mathrm{ml}$. The proteoglycan is 8 times more cytotoxic for malignant cells than for their normal counterparts. $100 \mu \mathrm{g} / \mathrm{ml}$ of proteoglycan produced $50 \%$ in vitro lyses of normal human erythrocytes. The result of this the saffron corm proteoglycan causes plasma membrane damage. Treatment of heLa cells with saffron proteoglycan results in cell death that correlates with important morphological changes in the plasma membrane (Escribano et al., 1996). The saffron proteoglycans show an intense cytotoxic effect as a result of plasma membrane alterations
(Abdullaev et al., 2003). Further research is required to identify the molecular targets of this glycoconjugate, as well as to elucidate both its biological function and biomedical uses.

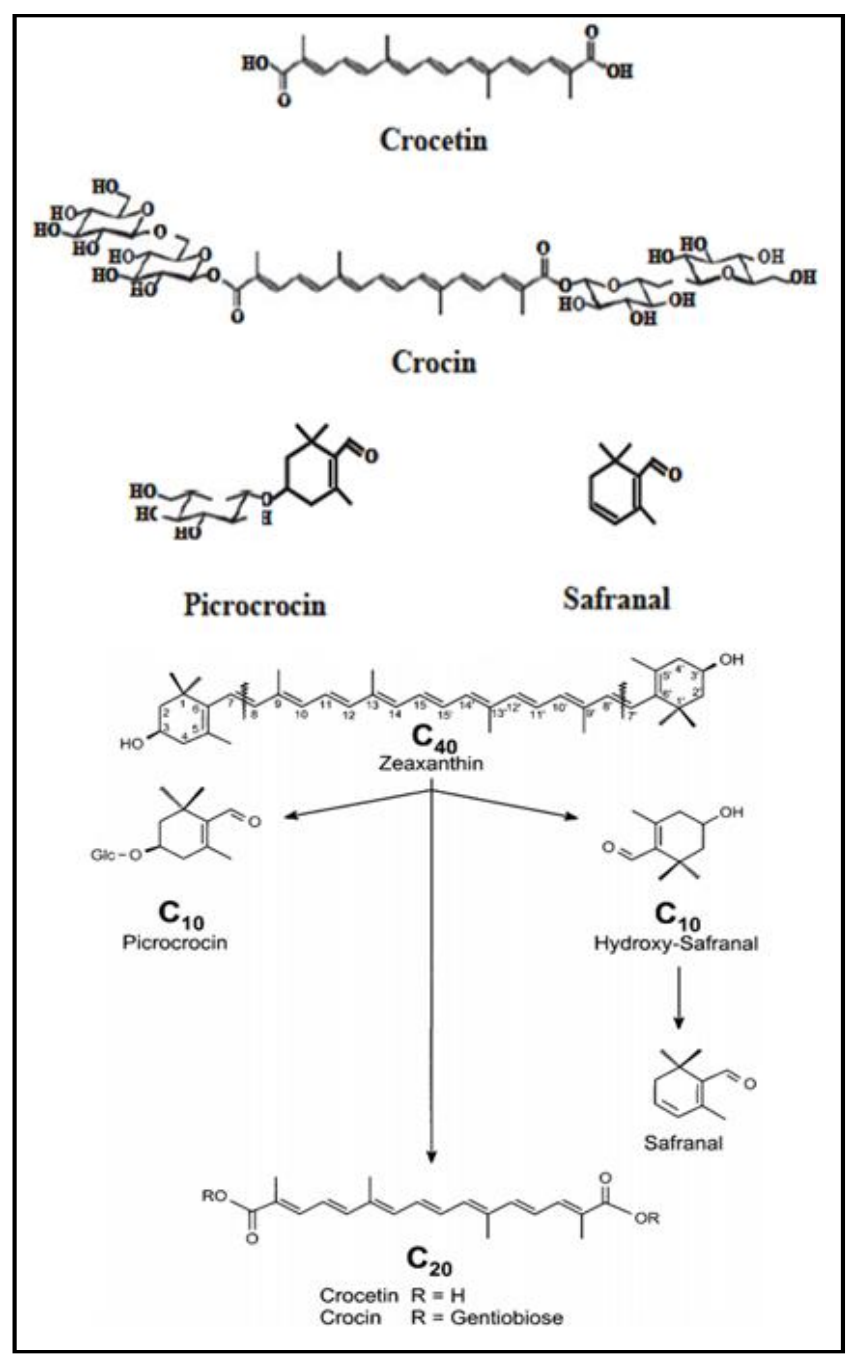

Figure 2: Chemical structures of phyto-constituents found in C. sativus

\subsection{Biological activity of saffron}

Saffron and their associated substances like carotenoids (zeaxanthin, lycopene, and various $\alpha$ - and $\beta$-carotenes) are extensively studied for their biomedical activity, especially for their chemoprevention activity against cancer because saffron has anticancer cells. Saffron also used in folk medicine as an anticancer agent against different kind of tumor and cancer. This research shows that possible future guaranteed use of saffron as an effective anticancer agent in clinical trials (Liakopulou-Kyriakides and Kyriakides, 2010).

Though, some of the volatile compounds viz., 2, 3-Butadiene, 2acetyl-pirroline, Acetic acid, Linalool, Hexanoic acid have been reported frequently from C. sativus, but till date approximately 160 bioactive volatile compounds have been identified in saffron. Gas chromatography (GC) and Mass spectroscopy (MS) is very important technique for the identification of chemical compounds. Dehydration process is very important for the identication of aroma, during dehydration process stigma loose $80 \%$ of their weight to 
preserve saffron for a long time. Its moisture contains reduced $12 \%$ determined by special technique. Degeneration of picrocin give rise to the aromatic compound called Safranal (Zarghami, 1970). Evans (1996) studied the biomedical properties of saffron and its potential use in cancer therapy and chemoprevention trials-chemoprevention strategies are very attractive and play a important role for controlling the incidence of cancer.

\subsection{Medicinal properties of Crocus sativus $\mathbf{L}$.}

Saffron has been used in conventional medicine in different nations for a variety of purposes such as an analgesic, tranquilizer, fever reducer, cure for pertussis and asthma, expectorant, antispasmodic, aphrodisiac, digestive, and carminative (Hosseinzadeh and Nassiri-Asl, 2013).

\subsubsection{Significance of saffron in traditional systems of medicines}

Saffron holds a variety of uses among the conventional medicinal systems of India and abroad. In India it is used as a precious herb in ayurvedic medicines for the treatment of arthritis, impotence and infertility. The other uses of saffron in ayurveda includes: Curing asthma and cough, useful in colds, treatment of alcoholism, cure acne and skin disease, preparation of chyawanprash, etc. In unani system of medicines this herb is used in medicine that reduced inflammation, in the treatment of enlarged liver and infection of urinary bladder and kidneys, to cure menstrual disorders, for strengthening the heart and as nervine tonic (Zargari, 1990).

\subsubsection{Saffron in western medicines}

Saffron is a most expensive spice and western world initially used it as spice. Later on its phytochemistry has been done and it was discovered as saffron a health tonic with no side effects. About $50 \mathrm{ml}$ of saffron dissolved in $200 \mathrm{ml}$ of milk with 1 spoon full sugar is added it makes a very healthy and yummy drink work as a health tonic. A regular intake of this everyday for a period of time enables the body to build resistance against a lot of common disease such as-asthma, fever, cold and cough (Abdullaev, 1993).

\subsection{Pharmacological uses of Saffron}

\subsubsection{Antihypertensive activity}

Fatehi et al. (2003) studied the effects of Saffron petals' extract on the blood pressure in sedated rats and also investigated the responses of the secluded rat and found an induction by electrical field stimulation (EFS). Ethanolic and aqueous extracts specific doses of Saffron petals' was found helpful in reducing the blood pressure.

\subsubsection{Anticonvulsant activity}

The anticonvulsant action of $C$. sativus stigma derived constituents, viz., safranal and crocin, were assessed in mice via pentylenetetrazole (PTZ)-induced convulsions in rats. Specific doses $(0.15$ and $0.35 \mathrm{ml} /$ $\mathrm{kg}$ body weight, i.p.) of safranal were found to reduce the convulsion extent, postponed the beginning of tonic convulsions, and saved the rats from death (Hosseinzadeh and Talebzadeh, 2005).

\subsubsection{Antigenototoxic and cytotoxic effects of saffron}

The entire isolated carotenoid ingredients of $C$. sativus confirmed in vitro cytotoxic activity against tumor cells. Crocin derivatives exerted a potent inhibitory consequence on the colonization of tumor cells. The results advocate that saffron itself, and its carotenoids can be used as potential cancer chemopreventive agents (Abdullaev et al., 2003).

\subsubsection{Effect on sexual behavior}

Hosseinzadeh et al. (2008) studied the aphrodisiac action of aqueous extract of saffron stigma and its components (safranal and crocin) in male rats. They used various doses to evaluate mount latency (ML), Mounting frequency (MF), ejaculation latency (EL) and intromission latency (IL). It was found that all doses of crocin and the extract (doses 160 and $320 \mathrm{mg} / \mathrm{kg}$ body wt.) have increased the IF, MF, and EF behaviors and shortened the parameters loke EL, IL, and ML. However, Safranal did not demonstrate any aphrodisiac properties.

\subsubsection{Anxiolytic action}

Pitsikas et al. (2008) conducted an investigation in rodents to assess the anxiolytic properties of crocins. They found that either crocins $(50 \mathrm{mg} / \mathrm{kg})$, which did not persuade animals' motor movement, or diazepam $(1.5 \mathrm{mg} / \mathrm{kg})$, augmented the latency. They concluded that treatment with these bioactive components of saffron induces anxiolytic effects in the mice.

\subsubsection{Antinociceptive and anti-inflammatory effects}

Stigma and petal extracts showed antinociceptive effects in chemically tempted pain analysis in addition to acute and/or chronic anti-inflammatory action, and these effects exist due to the occurrence of flavonoids, anthocyanins, tannins, saponins and alkaloids (Hosseinzadeh and Younesi, 2002)

\subsubsection{Relaxant possessions}

Nemati and Boskabady (2008) studied the mechanism(s) of the relaxant effects of saffron. They evaluated the stimulatory effect of aqueous-ethanolic extracts of this plant along with its component, safranal, on $\beta$-adrenoreceptors in tracheal chains of the guinea pigs. The results specified a comparatively effective stimulatory outcome of the extract from saffron on $\beta 2$-adrenoreceptors, to some extent due to its component, safranal.

\subsubsection{Effect on depression}

The efficiency of saffron's petal was evaluated in the cure of mildto-moderate hopelessness in a 6-week double-blind, placebocontrolled and randomized experiment. The results showed that the significant effectiveness of petal in the treatment of mild-tomoderate depression (Moshiri et al., 2006).

\subsubsection{Effect on learning behavior and long-term potentiation}

The saffron extract and its main ingredients, crocetin and crocin enhanced remembrance and learning ability in mice and rats which had ethanol induced learning behavior impairments. Oral doses of saffron may be helpful in the cure of neurodegenerative confusion states and other reminiscence mutilation (Sigiura et al., 1995; Abe and Saito, 2000).

\subsubsection{Effects on ocular blood flow and retinal function}

Isolated analogs of crocin from $C$. sativus considerably increased the flow of blood in the choroid and retina in addition to make easy the retinal function recuperation and it could be used to care for agerelated macular degeneration or ischemic retinopathy (Xuan, 1999). 


\subsubsection{Effect on coronary artery disease}

In an experiment 50 milligrams of saffron dissolved in $100 \mathrm{ml}$ milk and it was given twice a day to selected persons, and a noteworthy decline in lipoprotein oxidation propensity in those person affected with coronary artery disease (CAD) signifies the impending of C. sativus as an antioxidant (Verma and Bordia, 1998).

\section{Conclusion}

Though, spices, namely; Cinnamomum verum J. Presl, Trigonella foenum-graecum L., and Crocus sativus L., are used in a day-today life as essential ingredients of many recipes, but they have specific medicinal importance and recognized as the integral components of the traditional medicinal system to cure many diseases. They contain certain essential oils, phenolic compounds, flavonoids and many more useful components. Each and every property of their phytochemicals plays important roles in human health progression. They have antioxidant, antimicrobial, anticancer, anti-inflammatory and antidiabetic activities and become more precious for the modern healthcare systems than the past. In recent past, various medicinal importance of these species have been explored and established in the treatment of curing cancer, cardiac and nervous disease.

\section{Future Prospect}

Till date, many phytochemicals have been extracted from these spices that are used for making novel medicines to cure several diseases such as cancer, cardiac problems, HIV, multiple sclerosis, chronic wounds, and Alzheimer's disease. Though, a lot of work has been done on these spices, but their value seems to be never ending therefore more efforts are required to fully explore the utilities of these spices in health related issues, both as neutraceuticals and pharmceutical prospectives. In many studied cases, due lack of clinical trials regarding antibodies effects and chemicals included in it, the clarity in chemical efficiency is not available yet. But there is great scope of further analysis with the aid of newer and future advances, including molecular approaches for the production of more bioactive compounds and formation of novel biomolecules natural remedies.

\section{Acknowledgements}

I acknowledge the Bioinformatics Center, Banasthali Vidyapith supported by DBT for providing computation support, and DST for providing networking support through the FIST program at the Department of Bioscience and Biotechnology. I also acknowledge help attain from my PG students Ms. Supriya Sharma, Neha Yadav and Nikita Gautam during the compilation of this article.

\section{Conflict of interest}

The author declared that there is no conflicts of interest in the course of conducting the research. The author has final decision regarding the manuscript and decision to submit the findings for publication.

\section{References}

Abdalla Wisal, G. (2018). Antibacterial and antifungal effect of Cinnamon. Microbiology Research Journal International, 23(6):1-8.

Abdullaev, F.J. (1993). Biological effects of saffron. Biofactors, 4:83-86.

Abe, K. and Saito, H. (2000). Effects of saffon and its constituent crocin on learning behavior and long-term potentiation. Phytotherapy Research, 14:149-52.
Acharya, S.N.; Acharya, K.; Paul, S. and Basu, S.K. (2011). Variation in the antioxidant and anti-leukemic properties among different Western Canada grown fenugreek (Trigonella foenum-graecum L.) genotypes. Canadian Journal of Plant Science, 91(1):99-105. DOI: $10.4141 /$ cjps 10025 .

Acharya, S.N.; Blade, S.; Mir, Z. and Moyer, J.S. (2007). Tristar fenugreek. Canadian Journal of Plant Science, 87:901-903. DOI: 10.4141/ P06-047.

Acharya, S.N.; Thomas, J.E. and Basu, S.K. (2006). Fenugreek: An "old world" crop for the "new world". Biodiversity, 7(3\&4):27-30. DOI: 10.1080 / 14888386.2006.9712808.

Ahmed, M.A.; Ibrahim, O.M. and Elham, A.B. (2010). Effect of bio and mineral phosphorus fertilizer on the growth, productivity and nutritional value of fenugreek (Trigonella foenumgraecum L.) in Newly Cultivated Land. Research Journal of Agriculture and Biological Sciences, 6(3):339-348.

Ahvazi, M.; Khalighi-Sigaroodi, F.; Charkhchiyan M.M.; Mojab, F.; Mozaffarian, V.A. and Zakeri, H. (2012). Introduction of medicinal plants species with the most traditional usage in the alamut region. Iranian Journal of Pharmaceutical Research, 11:185-194.

Alam, A. and Sharma, v. (2012). Textbook of Economic Botany. Pointer Publisher, Jaipur, pp:317.

Al-Asmari, A.K.; Albalawi, S.M.; Athar, M.T.; Khan, A.Q.; Al-Shahrani, H. and Islam, M. (2015). Moringa oleifera as an anti-cancer agent against breast and colorectal cancer cell lines. PLoS One, 10(8):e0135814.

Ansari, M.H.R. and Ahmad, S. (2019). Herbs that heal: Natural remedies for health promotion and longevity. Ann. Phytomed., 8(1):7-18.

Balijepalli, M.K.; Buru, A.S.; Sakirolla, R. and Pichika, M.R. (2017). Cinnamomum genus: A review on its biological activities. International Journal of Pharmacy and Pharmaceutical Sciences, 9(2):1-11.

Basch, E.; Ulbricht, C.; Kuo, G.; Szapary, P. and Smith, M. (2003). Therapeutic applications of fenugreek. Alternative Medicine Review, 8(1):20-27.

Basu, S.K. and Agoramoorthy, G. (2014). Fenugreek (Trigonella foenumgraecum L): Production challenges and opportunities for Asia, Africa and Latin America. American Journal of Social Issues and Humanities, Fenugreek Special Issue (March/April) pp:1-2.

Cardoso-Ugarte, G.A.; López-Malo, A. and Sosa-Morales, M.E. (2016). Cinnamon (Cinnamomum zeylanicum) Essential Oils. In: Essential Oils in Food Preservation, Flavor and Safety (Preedy, V.R.), Ch. 38: 339-347. doi:10.1016/b978-0-12-416641-7.00038-9

Cheng, S.; Liu, J.; Hsui, Y. and Chang, S. (2006). Chemical polymorphism and antifungal activity of essential oils from leaves of different provenances of indigenous cinnamon (Cinnamon osmophloeum). Bioresource Technology, 97(2):306-312.

Cheng, S.; Liu, J.; Huang, C.; Hsui, Y.; Chen, W. and Chang, S. (2009). Insecticidal activities of leaf essential oils from Cinnamomum osmophleum against three mosquito species. Bioresource Technology, 100(1): 457-464.

Chevallier, A. (2000). The encyclopedia of herbal medicine. 2nd edition Dorling Kindersley, Ltd. London.

Chevassus, H.; Gaillard, J.B.; Farret, A.; Costa, F.; Gabillaud, I.; Mas, E.; Dupuy. A.M.; Michel, F.; Cantié, C.; Renard, E.; Galtier, F. and Petit, P. (2010). A fenugreek seed extract selectively reduces spontaneous fat intake in overweight subjects. European Journal of Clinical Pharmacology, 66(5):449-455.

Dar, A.R.; Shahnawaz, M. and Qazi, H.P. (2017). General overview of medicinal plants: A review. The Journal of Phytopharmacology, 6:349-351.

Dhuley, J.N. (1999). Antioxidant effects of cinnamon (Cinnamomum verum) bark and greater cardamon (Amomum subulatum) seeds in rats fed high fat diet. Indian Journal of Experimental Biology, 37(3):238-242.

Dinarello, C.A. (2006). The paradox of pro-inflammatory cytokines in cancer. Cancer and Metastasis Reviews, 25:307-313.

Dugoua, Jean-Jacques; Seely, D.; Perri, D.; Cooley, K.; Forelli, T.; Mills, E. and Koren G. (2007). From type 2 diabetes to antioxidant activity: A systematic review of the safety and efficacy of common and cassia cinnamon bark. Canadian Journal of Physiology and. Pharmacology, 85:837-847. 
Duke, A.J. (1986). Handbook of legumes of world economic importance, Plemus Press, New York and London. pp:345.

Encyclopaedia Britannica (1974). Saffron. Vol. 9. Chicago, IL: Encyclopaedia Britannica Inc., Encyclopaedia Britannica, pp:891.

Escribano, J.; Alonso G.L.; Coca-Prados, M. and Fernandez, J.A. (1996). Crocin, safranal and picrocrocin from saffron (Crocus sativus L.) inhibit the growth of human cancer cells in vitro. Cancer Letters, 100:23-30.

Ethan, B.; Grace, K. and Michael, S. (2003). Therapeutic applications of fenugreek. Alternative Medicine Review, 8(1):20-27.

Evans, W.C. (1996). Trease and evans-pharmacognosy. China: Saunders $\mathbb{C}$ Elsevier Limited, pp:438.

Fatehi, M.; Rashidabady, T. and Fatehi-Hassanabad, Z. (2008). Effects of Crocus sativus petals extract on rat blood pressure and on response induced by electrical field stimulation in the rat isolated vas deferens and guinea-pig ileum. Journal of Ethnopharmacology, 84:199-203.

Ferlay, J.; Shin, H.; Bray, F.; Forman, D.; Mathers, C. and Parkin, D. (2010). Cancer Inci-dence and mortality worldwide: IARC Cancer-Base No.10. International Agency for Research on Cancer, Lyon, France.

Gainer, J.W. and Chisolm, G.M. (1974). Oxygen diffusion and atherosclerosis. Athersclerosis, 19:135-138.

Gohari, A.R.; Saeidnia, S. and Mahmoodabadi, M.K. (2013). An overview on saffron, phytochemicals, and medicinal properties. Pharmacognosy Reviews, 7:61-66.

Gruenwald, J.; Freder, J. and Armbruester, N. (2010). Cinnamon and health Critical Reviews in Food Science and Nutrition, 50:822-834.

Guardia, T.; Rotelli, A.E.; Juarez, A.O. and Pelzer, L.E. (2001). Antiinflammatory properties of plant flavonoids. Effects of rutin, quercetin and hesperidin on adjuvant arthritis in rat. Farmaco., 56(9):683-687.

Hamidpour, R.; Hamidpour, M.; Hamidpour, S. and Shahlari. M. (2015). Cinnamon from the selection of traditional applications to its novel effects on the inhibition of angiogenesis in cancer cells and prevention of Alzheimer's disease, and a series of functions such as antioxidant, anticholesterol, antidiabetes, antibacterial, antifungal, nematicidal, acaracidal, and repellent activities. Journal of Traditional and Complementary Medicines, 5(2):66-70. doi:10.1016/ j.jtcme.2014.11.008

Hosseinzadeh, H. and Talebzadeh, F. (2005). Anticonvulsant evaluation of safranal and crocin from Crocus sativus in mice. Fitoterapia, 76:722-724

Hosseinzadeh, H. and Younesi, H. (2002). Petal and stigma extracts of Crocus sativus $L$. have antinoceceptive and anti-inflammatory effects in mice. BMC Pharmacology, 2:7.

Hosseinzadeh, H.; Ziaee, T. and Sadeghi, A. (2008). The effect of saffron, Crocus sativus stigma extract and its constituents, safranal and crocin on sexual behaviors in normal male rats. Phytomedicine, 15:491-495.

Jakhetia, V.; Patel, R. and Khatri, P. (2010). Cinnamon: A pharmacological review. Journal of Advanced Scientific Research, 1(2):19-12.

Jamshidi-Kia, F.; Loriogooini, Z. and Amini-Khoei, H. (2018). Medicinal plants: Past history and future perspective. Journal of Herbmed Pharmacology, 7:1-7.

Jayaprakasha, G.; Jaganmohan, L. and Sakariah, K. (2000). Chemical composition of the flower oil of Cinnamomum zeylanicum Blume. Journal of Agriculture and Food Chemistry, 48(9),4294-4295.

Kamran, U.; Bhatti, H.; Jamil, S. and Muhammad, Z. (2018). Biogenic synthesis, characterization and investigation of photocatalytic and antimicrobial activity of manganese nanoparticles synthesized from Cinnamomum verum bark extract. Journal of Molecular Structure, 1179:532-539. 10.1016/j.molstruc.2018.11.006.

Kuete, V.; Karaosmanoðlu, O. and Sivas, H. (2017). Anticancer activities of african medicinal spices and vegetables. Medicinal spices and vegetables from Africa. In: Therapeutic potential against metabolic, inflammatory, infectious and systemic diseases (Ed. Kuete, V.), pp:271-297. doi:10.1016/b978-0-12-809286-6.00010-8
Lee, H.S.; Kim, B.S. and Kim, M.K. (2002). Suppression effect of Cinnamomum cassia bark-derived component on nitric oxide synthase. Journal of Agricultural and Food Chemistry, 50(26):7700-7703.

Lepage, C.; Liagre, B.; Cook-Moreau, J.; Pinon, A. and Beneytout, J.L. (2010). Cyclooxygenase-2 and 5-lipoxygenase pathways in diosgenininduced apoptosis in HT-29 and HCT-116 colon cancer cells. International Journal of Oncology, 36(5):1183-1191.

Leung, A.Y. and Foster, S. (Eds.) (1996). Encyclopedia of common natural ingredients used in food, drugs and cosmetics. John Wiley \& Sons, New York. pp:605.

Li, C.J.; Huang, S.Y.; Wu, M.Y.; Chen, Y.C.; Tsang, S.F. and Chyuan, J.H. (2012). Induction of apoptosis by etha-nolic extract of Corchorus olitorius leaf in human hepatocellular carcinoma (HepG2) cells via a mito-chondria-dependent pathway. Molecules, 17(8):9348-9360.

Liagre, B.; Bertrand, J.; Leger, D.Y. and Beneytout, J.L. (2005). Diosgenin, a plant steroid, induces apoptosis in COX-2 deficient K562 cells with activation of the p38 MAP kinase signalling and inhibition of NFkappaB binding. International Journal of Molecular Medecine, 16:1095-1101.

Liagre, B.; Leger, D.Y.; Vergne-Salle, P. and Beneytout, J.L. (2007). MAP kinase subtypes and aktregulate diosgenin-induced apoptosis of rheumatoid synovial cells in association with COX-2 expression and prostanoid production. International Journal of Molecular Medicines, 19:113-122.

Liagre, B.; Vergne-Salle, P.; Corbiere, C.; Charissoux, J.L. and Beneytout, J.L. (2004). Diosgenin, a plant steroid, induces apoptosis in human rheumatoid arthritis synoviocytes with cyclooxygenase-2 overexpression. Arthritis Research and Therapy, 6:R373-R383.

Liakopulou-Kyriakides, M. and Kyriakides, D.A. (2002). Crocus sativusBiological active Constituents. Studies in Natural Products Chemistry, 26:293-312.

Lopez, P.; Sanchez, C.; Batlle, R. and Nerin, C. (2005). Solid- and vapor-phase antimicrobial activities of six essential oils: Susceptibility of selected foodborne bacterial and fungal strains. Journal of Agriculture and Food Chemistry, 53:6939-6946. doi:10.1021/ jf050709v. PMID: 16104824.

Mallavarapu, G.R.; Ramesh, S.; Chandrasekhara, R.S.; Rajeswara Rao, B.R.; Kaul, P.N. and Battacharya, A.K. (1995). Investigation of the essential oil of cinnamon leaf grown at Bangalore and Hyderabad. Flavour Fragrance Journal, 10:239-242.

Mancini-Filho, J.; Van-Koiij, A.; Mancini, D.A.; Cozzolino, F.F. and Torres, R.P. (1998). Antioxidant activity of cinnamon (Cinnamomum zeylanicum Breyne) extracts. Bollettino. Chimico. Farmaceutico., 137:443-447.

Manoranjotham, M.; Ramaraj, T. and Kamaraj, M. (2016). An ethnobotanical study on traditional uses of medicinal plants in Musiri Taluk, Tiruchirappalli District, Tamil Nadu. Journal of Applied and Advanced Research, 1(3):16-24. doi: 10.21839/jaar.2016.v1i3.30

Mathew, S. and Abraham T.E. (2006). Studies on the antioxidant activities of cinnamon (Cinnamomum verum) bark extracts, through various in vitro models. Food Chemistry, 94(4):520-528.

McAnuff, M.A.; Omoruyi, F.O.; Morrison, E.Y. and Asemota, H.N. (2005). Changes in some liver enzymes in streptozotocin-induced diabetic rats fed sapogenin extract from bitter yam (Dioscorea polygonoides) or commercial diosgenin. West Indian Medical Journal, 54(2):97-101.

Mehrafarin, A.; Qaderi, A.; Rezazadeh, S.; Naghdi Badi, H.; Noormohammadi G. and Zand, E. (2010). Bioengineering of important secondary metabolites and metabolic pathways in fenugreek (Trigonella foenum graecum L.). Journal of Medicinal Plants, 9(35):1-18.

Mita Vakilwala, K.M. and Tande, A. (2017). Phytochemical analysis and antimicrobial activity of Cinnamomum verum. International Journal of Research and Scientific Innovation, 4(4):69-74.

Mollazadeh, H. and Hosseinzadeh, H. (2016). Cinnamon effects on metabolic syndrome: A review based on its mechanisms. Iranian Journal of Basic Medical Sciences, 19(12):1258-1270. doi:10.22038/ijbms.2016.7906.

Moradi kor, N.; Didarshetaban, M.B. and Saeid Pour, H.R. (2013). Fenugreek (Trigonella foenum-graecum L.) as a valuable medicinal plant. International Journal of Advanced Biological and Biomedical Research, 1(8):922-931. 
Moshiri, E.; Basti, A.A.; Noorbala, A.A.; Jamshidi, A.M.; Abbasi, S.H. and Akhondzadeh, S. (2006). Crocus sativus L. (petal) in the treatmen of mild-to-moderate depression: A double-blind, randomised and placebo-controlled trial. Phytomedicine, 13:607-611.

Nabavi, S.F.; Di Lorenzo, A.; Izadi, M.; Sobarzo-Sánchez, E.; Daglia, M. and Nabavi, S.M. (2015). Antibacterial effects of Cinnamon: From farm to food, cosmetic and pharmaceutical industries. Nutrients, 7(9):7729-7748. doi: $10.3390 /$ nu 7095359

Nair, S.C.; Pannikar, B. and Pannikar, K.R. (1991). Antitumour activity of saffron. Cancer Letters, 57:109-114.

Nemati, H.; Boskabady, M.H. and Ahmadzadef Vortakolaei, H. (2008). Stimulatory effects of Crocus sativus (Saffron) on $\beta 2$ adrenoreceptors of guinea pig tracheal chains. Phytomedicine, 15:1038-1045.

Nooreen, Z.; Rai, V.K. and Yadav, N.P. (2018). Phytopharmaceuticals: A new class of drug in India. Ann. Phytomed., 7(1):27-37.

Osuna, L.; Tapia, M. and Aguilar, A. (2005). Medicinal plants of the traditional mexican medicine to treat gastrointestinal infections. Universitat de Barce-lona, Spain. pp:175.

Paranagama, P.A.; Wimalasena, S.; Jayatilake, G.S.; Jayawardena, A.L.; Senanayake, U.M. and Mubarak, A.M. (2010). A comparison of essential oil constituents of bark, leaf root and fruit of cinnamon (Cinnamomum zeylanicum Blume.), grown in Sri Lanka. Journal of Natural Science Foundation, Sri Lanka, 29:147-153.

Peterson, D.; George, R.; Scaramozzino, F.; Lapointe, N.; Graves, D. and Lew, J. (2009). Cinnamon extract inhibits tau aggregation associated with Alzheimer's disease in vitro. Journal of Alzheimer's Disease, 17:585-597. 10.3233/JAD-2009-1083.

Petropoulos, G.A. (2002). Fenugreek, The genus Trigonella. Taylor and Francis, London and New York. pp:255.

Pitsikas, N.; Boultadakis, A.; Gergiadou, G.; Tarantilis, P.A. and Sakellaridis, N. (2008). Effects of the active constituents of Crocus sativus L. in an animal model of anxiety. Phytomedicine, 15:1135-1139.

Ranasinghe, L.; Jayawardena, B. and Abeywiwickrama, K. (2005). An integrated strategy to control post-harvest decay of Embul banana by combining essen-tial oils with modified atmosphere packaging. International Journal of Food Science and Technology, 40(1):97-103.

Rao, P.V. and Gan, S.H. (2014). Cinnamon: A multifaceted medicinal plant. Evidence Based Complementary and Alternative Medicines, pp:642942. doi:10.1155/2014/642942.

Reddy, K. (2017). Green synthesis, morphological and optical studies of CuO nanoparticles. Journal of Molecular Structure. 1150(15):553-557. doi: $10.1016 /$ j.molstruc.2017.09.005

Roussel, A.; Hininger, I.; Benaraba, R.; Ziegenfuss, T.N. and Anderson, R.A (2009). Antioxidant effects of a cinnamon extract in people with impaired fasting glucose that are overweight or obese. Journal of the American College of Nutrition, 28:16-21.

Sakr, S.A.; Mahran, H.A.; and Abo-El-Yazid, S.M. (2009). Fenugreek (Trigonella foenum-graecum) ameliorates cyclophosphamide-induced histopathological, histochemical and biochemical changes in the liver of albino mice. The Egyptian Society of Experimental Biology, 5:331-339.

Senanayake, U.M.; Lee, T.H. and Wills, R.B.H. (1978). Volatile constituents of cinnamon (Cinnamomum zeylanicum) oils. Journal of Agricultural and Food Chemistry, 26(4):822-824.

Shabbeer, S.; Sobolewski, M.; Anchoori, R.K.; Kachhap, S.; Hidalgo, M.; Jimeno, A.; Davidson, N.E.; Carducci, M. and Khan, S.R. (2009) Fenugreek: A naturally occurring edible spice as an anticancer agent. Cancer Biology Therapy, 8(3):272-278.

Shakya, K.A. (2016). Medicinal plants: Future source of new drugs. International Journal of Herbal Medicine, 4(4):59-64.
Shan, B.; Cai, Y.Z.; Sun, M. and Corke, H. (2005). Antioxidant capacity of 26 spice extracts and characterization of their phenolic constituents. Journal of Agriculture and Food Chemistry, 53:7749-7759. doi:10.1021/jf051513y.

Sharma R.D.; Sarkar, A. and Hazra D.K. (1996). Hypolipidaemic effect of fenugreek seeds: A chronic study in non-insulin dependent diabetic patients. Phytotherapy Research, 10:332-334.

Sharma, R.D.; Raghuram, T.C. and Rao, N.S. (1990). Effect of fenugreek seeds on blood glucose and serum lipids in type I diabetes. European Journal of Clinical Nutrition, 44:301-306.

Sharma, V. and Alam, A. (2018). Ethnobotany. Rastogi Publications, Meerut, pp:384.

Shekha, M.S.; Qadir, A.B.; Ali, H.H. and Selim, X.E.. (2014). Effect of fenugreek (Trigonella foenum-graecum) on ethylene glycol induced kidney stone in rats. Jordan Journal of Biological Sciences, 7:257-260.

Sigiura, M.; Saito, H. and Abe, K. (1995). Ethanol extract of Crocus sativus L. antagonizes the inhibitory action of ethanol on hippocampal long-term potentiation in vivo. Phytotherapy Research, 9:100-104.

Singh, G.; Maurya, S.; DeLampasona, M.P. and Catalan, C.A. (2007). A comparison of chemical, antioxidant and antimicrobial studies of cinnamon leaf and bark volatile oils, oleoresins and their constituents. Food and Chemical Toxicology, 45:1650-1661.

Singh, R. (2015). Medicinal Plants: A review. Journal of Plant Sciences, 3:50-55.

Snehlata, H.S. and Payal D.R. (2011). Fenugreek (Trigonella foenumgraecum L.): An overview. International Journal of Current Pharmaceutical Review and Research, 2:169-187.

Srivastava, R.; Ahmed, H.; Dixit, R.K.; Dharamveer; Saraf, S.A. (2010). Crocus sativus L.: A comprehensive review. Pharmacognosy Reviews, 4(8):200-208

Suhaj, M. (2006). Spice antioxidants isolation and their antiradical activity: A review. Journal of Food Composition and Analysis, 19(6-7):531-537.

Thirunavukkarasu, V.; Anuradha, C.V. and Viswanathan, P. (2003). Protective effect of fenugreek (Trigonella foenum graecum) seeds in experimental ethanol toxicity. Phytotherapy Research, 17(7):737-743.

Thomas, J.; Bahuchets, S.; Epelboin, A. and Furniss, S. (2003). Encyclopédie des Pygmées Aka: Techniques, Langage et Société des ChasseursCueilleurs de la Forêt Centrafricaine (Sud-Centrafrique et NordCongo), Vol. 11. Editions Peeters-SELAF, Paris, pp:1981-2010.

Toriizuka, K. (1998). Basic lecture of Kampo medicine: Pharmacological effect of cinnamon. Kampo. Med., 11:431-436.

Vazirian, M.; Alehabib, S.; Jamalifar, H.; Fazeli, R.; Toosi, A. and Khanavi, M. (2015). Antimicrobial effect of cinnamon (Cinnamomum verum J. Presl) bark essential oil in cream-filled cakes and pastries. Research Journal of Pharmacognosy, 2:11-16.

Verma, S.K. and Bordia, A. (1998). Antioxidant property of saffron in man. Indian Journal of Medical Science, 52:205-207.

Xuan, B. (1999). Effects of crocin analogs on ocular flow and retinal function. Journal of Ocular Pharmacology and Therapeutics, 15: $143-152$

Yang, S.K.; Yusoff, K.; Ajat, M.; Thomas, W; Abushelaibi, A.; Akseer, R.; Lim, E. and Lai, Kok-Song. (2019). Disruption of KPC-producing klebsiella pneumoniae membrane via induction of oxidative stress by cinnamon bark (Cinnamomum verum J. Presl) essential oil. Plos. One, 14(4):1-20. e0214326. 10.1371/journal.pone.0214326.

Zargari, A. (1990). Medicinal Plant. Tehran: Tehran University Press; pp:574.

Zarghami, N.S. (1970). The volatile constituents of saffron (Crocus sativus L.). Ph.D. Thesis, Univ. California, Davis, CA. 